\title{
Or^яan, ^eкuiї
}

ASSOCIATION BETWEEN OCCUPATIONAL

ASTHENOPIA AND THE PSYCHOPHYSIOLOGICAL

INDICATORS OF VISUAL FATIGUE FOR VDT WORIKERS

\author{
Ustinaviciene Ruta', Januskevicius Vidmantas ${ }^{2}$ \\ 'Department of Environmental and Occupational Medicine, \\ Kaunas University of Medicine, Lithuania, \\ ${ }^{2}$ Department of Health Systerns Research of Institute of Biomedical Research, \\ Kaunas University of Medicine, Lithuania
}

To evaluate the relationship of functional visual fatigue parameters with the symptoms of asthenopia, and to determine association between subjective and the objective indicators of eye fatigue. 404 office workers with and without VDT work were selected for the inclusion in the study. To evaluate visual fatigue was used questionnaire for subjective complaints and measurement of main ophtalmological indicators. Psychophysiological studies determine changes in the sensomotoric reactions during the working day and the working week; in addition to that, studies of the constancy of clear-unclear vision and the fluctuation of the clear and unclear vision periods were performed. Measurements of psychophysiological changes were taken over one week, three times per day, for five days in a row. The questionnaire data showed that $88.4 \%$ of all employees complained of various vision disorders. Our psychophysiological findings showed that during the second half of the working day, when general fatigue and asthenopia develops, ophthalmologic indications change: visual sensomotor reaction becomes slower, the duration of the periods of unclear vision increases, and the change of the periods of clear and unclear vision becomes faster. Changes in the ocular and psychophysiological functions before and at the end of the workday, as determined in our study, provide a good objective index of VDT-induced «oculars and central nervous system fatigue, can be used for intervention research.

Key words: Ergophtalmology, Visual fatigue, Occupational asthenopia, VDT work, Eye discomforts, Psychophysiclogy

\section{Background}

Computers aggressively and inexorably penetrate into our daily life and work. The number of non-computerized workplaces is decreasing. Computers ensure faster performance of work tasks, but at the same time they also stipulate greater control of the work, higher workloads, few decision-making possibilities, more cognitive processing and visual strain, and less physical expenditure of energy ${ }^{1}$. Literature presents a variety of health disorders associated with computer work, but the main symptoms are related to the vision apparatus ${ }^{2-5}$ ). Various symptoms of visual discomforts are recorded more often in VDT operators than in office workers doing comparable jobs without VDTs. VDT work is recognized as a risk factor for visual fatigue and asthenopia ${ }^{6-9}$ ). Causal factors for these observations are found in the design of the equipment, workplace, and the work tasks ${ }^{4}$ ). Asthenopia is defined as a complex of subjective factors ${ }^{5}$, whereas visual fatigue is reflected by both subjective and objective studies. Nevertheless, the mechanisms underlying the increased fatigue of the vision apparatus have not yet been fully investigated, at the same time some very profound and conclusive investigations are done $\mathrm{e}^{7,10-12)}$. Considering the physiological impact of the job itself, an increase in visual fatigue together with the factors of the work environment might contribute substantially to the increased risk of vision damage. The increased central nervous system fatigue can influence working capacity of the eye function. There is a need for objective evaluation of asthenopia and psychophysiological aspects of the VDT work. Using this knowledge, rational decisions can be made. Potentially expensive interventions, such as health surveillance or workplace redesign might not be defensible if decisions are made simply on the basis of the reported prevalence of subjective symptoms ${ }^{13)}$.

Although there are many contributions in the scientific literature aimed at the examination of functional changes of vision during VDT work, we were trying to find a correlation between asthenopia and the objective evaluation of the functional state of eyes and the central nervous system.

To eliminate the confounding effects of aging, gender, and characteristics of the work environment, groups for the investigation were selected so that they were similar, concerning their properties and work experience. Therefore, the aim of our study was to determine the relation. of functional visual fatigue on symptoms of asthenopia, and to evaluate the association between subjective and the objective indicators of the fatigue. 


\section{Materials and methods}

During 1997-2000, 404 office workers from six Kaunas city companies with and without VDT work were selected for the study. The study investigated 208 people working with computers, and 196 office employees from the control group. The groups of people working with computers, included those who spent more than 6 work hours at a computer daily. The control group included people doing sedentary office work (bookkeeping, management, and documentation work) characterized by similar levels of psycho-emotional and psychological stress. The study group consisted of $132(63.5 \%)$ women and $76(36.5 \%)$ men; mean age of that group was 33.8 years, and mean duration of computer work -7.6 years. The control group consisted of $137(69.9 \%)$ women and $59(30.1 \%)$ men; mean age of that group was 35.4 years, and mean work experience was 9.8 years. All subjects agreed to participate in the study. The investigated persons were not restricted in terms of their normal workday activities and were acting as they usually do when working.

The questionnaire-based inquiry was used to evaluate the subjective complaints of subjects during their work time, and the symptoms of visual fatigue. Measurements of the ophthalmologic indicators were taken on Monday morning, before the work start. This time was selected to avoid any biases of ophthalmologic data due to a visual workload. The ophthalmologic study investigated vision acuity, refraction, accommodation (absolute and relative), the nearest point of convergence, the anterior segment of the eye, and ocular fundus. A part of randomly selected people ( 54 people working with computers, and 56 people from the control group) underwent tear film stability investigation, using tear film break-up time in slit-lamp method.

Psychophysiological studies were applied to determine changes in the sensomotor reaction to light and sound during the working day and the working week; in addition, studies of the constancy of clear-unclear vision and the fluctuation of the clear and unclear vision periods were performed. Measurements of psychophysiological changes were taken over one week, three times per day: before work, in the middle of the workday and after work, for five days successively. Each person was studied for 15 times within a week. The studies of sensomotor reactions and the constancy of clear vision were performed using an automated equipment complex PAV-1 (Russia). The mean sensomotor reaction and its deviation during each study were calculated on 32 samples. The studies of the constancy of clear vision and its periodical changes were performed for 3 minutes; mean indicators were calculated for 1 minute, using specialized vision tests and the data recording equipment.

The statistical analysis was performed on a personal computer with SPSS software. Values were expressed as a mean \pm standard deviation for each investigation. Variables between different times of investigation were compared by the t-test. Differences were considered statistically significant at $p<0.05$.

\section{Results}

The questionnaire data of people working with computers showed that $88.4 \%$ (357) of all employees complained of various vision disorders. The obtained findings showed that computer work mainly influences the vision analyzer. The subjects indicated 7 symptoms describing eye fatigue and damage.

All the aforementioned symptoms and disorders of the visual function indicate to the syndrome of the strain or fatigue of the visual analyzer, called asthenopia. The stability of asthenopia is characterized by the time, during which these symptoms disappear, and the visual function is restored. The clarification of symptoms of asthenopia and their prevalence in the studied and the control groups necessitates the determination of whether these symptoms appear on a daily basis or are relatively rare. According to findings of the performed studies, in $43 \%$ of all studied subjects the symptoms disappeared after finishing the work with a computer, in $45 \%$ of them they remained for several hours after work, and $12 \%$ of the studied subjects felt the symptoms during the following day. Table 1 shows that part of the aforementioned symptoms are observed only in people working with computers, and are not recorded in people of other professions. First of all, these symptoms include tearful eyes, soreness of the ocular conjunctiva, and flicker in the eyes during work. Although asthenopia may be diagnosed in the presence of only one symptom of those mentioned in Table 1, in order to make a more precise diagnosis of the visual fatigue, a group of 92 people was selected, where 2 or more subjective complaints were indicated. Within this group, of 92 people who complained of the visual fatigue, $29(31.5 \%)$ people experienced symptoms of asthenopia on a daily basis, $55(59.8 \%)$ people experienced symptoms $2-3$ times per week, and $8(8.7 \%)$ people experienced these symptoms several times a month.

In the control group, respectively, out of 38 people who reported separate symptoms of asthenopia, 9 (23.7 \%) people experienced these symptoms several times a week, and the rest $29(76.3 \%)$ people felt 
The prevalence ( $\%$ and cases) of symptoms of asthenopia among subjects and controls

\begin{tabular}{|l|c|c|}
\hline \multicolumn{1}{|c|}{ Symptom } & $\begin{array}{c}\text { Subjects working with computers, } \\
\% \text { and cases }\end{array}$ & $\begin{array}{c}\text { Control group, } \\
\% \text { and cases }\end{array}$ \\
\hline Redness of the eyes & $42.3 \%(88)$ & $1.5 \%(3)$ \\
\hline Ocular pain & $46.1 \%(96)$ & $3.6 \%(7)$ \\
\hline Tearful eyes & $17.3 \%(36)$ & $0 \%(0)$ \\
\hline Soreness of the ocular conjunctiva & $12.5 \%(26)$ & $0 \%(0)$ \\
\hline Unclear vision & $85.6 \%(178)$ & $10.7 \%(21)$ \\
\hline Flicker in the eyes & $18.3 \%(38)$ & $0 \%(0)$ \\
\hline Diplopia & $31.7 \%(66)$ & $3.6 \%(7)$ \\
\hline
\end{tabular}

these symptoms rarely, i.e. several times a month. In addition to that, people of the control group indicated that they experienced only one symptom - unclear vision or diplopia. In the group of people who worked with computers in the majority of cases reported $2-3$, and sometimes 4 and more symptoms the combination of which indicated to asthenopia.

Clinical ophthalmologic investigations of 208 people, who worked with computers showed, that $72.1 \%$ (150) of the subjects had different visual disorders. The majority of such cases were myopic changes of various degrees. According to the findings of the ophthalmologic examination, the degree of myopia ranged from $0.5 \mathrm{D}$ to $5.0 \mathrm{D}$, and in separate cases to $7.0 \mathrm{D}$. In the control group, $26.5 \%$ (52) of people had visual disorders. Table 2 shows the main findings of the ophthalmologic examination. Since the mean age of the case subjects and the controls are, respectively, 33.8 and 35.4 years, and the age distribution in both groups is equal, the findings are presented without dividing the subjects into aged groups.

As seen in the findings presented in Table 2, the major differences between the two studied groups were found in the analysis of the indicators of the extent of relative accommodation, and the proximal convergence point. Statistically reliable differences were also obtained in the evaluation of the refraction and the vision acuity without any correction. Statistical evaluation of the informative value of the findings, and the evaluation of the differences between two groups showed that relative accommodation was the most informative attribute. The second most informative attribute was proximal convergence point. Thus, these two latter examinations were the main ones in the determination of early visual disorders in people who worked with computers.

Ophthalmologic studies, including the examination of the frontal eye segment and ocular fundus revealed the following changes: hyperemia of the conjunctiva was detected in $47.1 \%(98)$ of people who worked with computers (case subjects), and in $6.6 \%$ (13) of the controls; individual cases of slight lens clouding were found in $9.6 \%$ (20) of the case subjects, and none - in the control group; I - Ilo myopic changes in the ocular fundus were detected in $37.5 \%$ (78) of the case subjects, and in $13.3 \%$ (26) of the controls; the ocular fundus of $8.7 \%$ (18) of the case subjects showed a deepened excavation of the visual nerve, while the percentage of such cases in the control group was $3.6 \%$ (7).

Iable 2

Ophtalmological investigation data

\begin{tabular}{|l|c|c|c|}
\hline \multicolumn{1}{|c|}{ Investigation } & $\begin{array}{c}\text { VDT workers } \\
(\mathbf{n = 2 0 8 )} \\
\text { mean } \pm \text { SD }\end{array}$ & $\begin{array}{c}\text { Control group } \\
(\mathbf{n}=\mathbf{1 9 6}) \\
\text { mean } \pm \text { SD }\end{array}$ & p \\
\hline Vision acuity, OD* & $0.62 \pm 0.35$ & $0.78 \pm 0.34$ & $<0.01$ \\
\hline Vision acuity, OS* & $0.65 \pm 0.29$ & $0.77 \pm 0.30$ & $<0.01$ \\
\hline Refraction OD, Diopter & $2.34 \pm 1.99$ & $3.54 \pm 1.36$ & $<0.01$ \\
\hline Refraction OS, Diopter & $2.17 \pm 1.82$ & $3.85 \pm 1.31$ & $<0.01$ \\
\hline Absoliut accomodation OD, Diopter & $1.86 \pm 1.59$ & $2.26 \pm 2.21$ & $<0.05$ \\
\hline Absoliut accomodation OS, Diopter & $1.94 \pm 1.91$ & $2.41 \pm 2.39$ & $<0.05$ \\
\hline Relative accomodation OD, Diopter & $3.99 \pm 2.39$ & $7.55 \pm 2.95$ & $<0.01$ \\
\hline Relative accomodation OS, Diopter & $4.20 \pm 2.35$ & $7.15 \pm 2.91$ & $<0.01$ \\
\hline Proximal convergence point, cm & $9.96 \pm 3.02$ & $8.43 \pm 2.16$ & $<0.01$ \\
\hline
\end{tabular}

*OD - right eye, $O S$ - left eye. 
During more deep ophthalmologic examinations, 54 randomly selected case subjects and 56 controls underwent studies of the tear film breaking time. Statistically reliable differences were found between people working with computers and the control group. Table 3 presents the obtained findings of the study that showing significant shortening in the tear film breaking time in people working with computers.

In order to evaluate computer operators' visual fatigue and working capacity, we used samples of the speed of sound and visual sensomotor reactions, the constancy of clear vision, and the changes in the periods of clear and unclear vision. That was useful for the evaluation of changes and differences in the working capacity and fatigue in the case subjects and the control groups during the working day and the working week.

Our obtained findings showed that during the second half of the working day, on developing the general fatigue and asthenopia, ophthalmologic indications were changing: visual sensomotor reaction was slowering, the duration of the periods of unclear vision increased, and the change of the periods of clear and unclear vision became faster.

Sensomotoric reaction in people working with computers was regularly worsening. The percentage expression of the changes in these findings is the following: $100 \%$ at the beginning of the work when the working capacity is the highest, $105.9 \pm 3.7 \%$ in the middle of the work, when fatigue develops, and 113.3 $\pm 7.5 \%$ after work. Visual sensomotor reaction in the control group changed less - the percentage dynamics of visual sensomotor reaction in the control group was as follows: $101.7 \pm 1.1 \%$ in the middle of the work, and $103.9 \pm 2.6 \%$ after work, compared to the findings obtained in this group before work.

In the study of the constancy of clear and unclear vision, frequency of changes of those periods, as well as their duration, were evaluated. In people working with computers, the development of visual fatigue results in a significant shortening of the period of clear vision. If before the work clear vision was $97.1 \pm 1.5$ $\%$ of all time, then in the middle it was $82.1 \pm 3.2 \%$, and at the end of the work $-61.9 \pm 4.2 \%$. The study of the control group where people's work was less associated with visual strain, showed a significantly lesser shortening the clear vision period (Table 4). The period of clear vision in the control group changed from $99.5 \pm 1.3 \%$ before work to $94.5 \pm 2.6 \%$ in the middle of the work, and to $89.1 \pm 2.5 \%$ after the work. The obtained findings allowed to state, that among computer operators, the period of clear vision during the working day shortened by $35.1 \%$, while in the control group - only by $10.4 \%(\mathrm{p}<0.01)$.

Summing up the presented findings, it can be stated that the changes in psycho-physiological indicators during the working day show that professional computer operators' indicators of the central nervous system, of the functional changes in the vision analyzer, and fatigue are statistically reliably greater. The findings of the performed psycho-physiological stud-

Table 3

Tear film stability time according to work characteristics

\begin{tabular}{|l|c|c|c|c|}
\hline \multirow{2}{*}{ Work characteristics } & \multirow{2}{*}{ Cases } & \multicolumn{2}{|c|}{ Tear film stability time mean \pm SD } & \multirow{2}{*}{ p } \\
\cline { 3 - 5 } & & Right eye & Left eye & $<0,01$ \\
\hline VDT work & 54 & $6,47 \pm 0,66$ & $6,39 \pm 0,65$ & $<0,01$ \\
\hline Control group & 56 & $19,9 \pm 2,09$ & $20,4 \pm 1,96$ & $<$ \\
\hline
\end{tabular}

${ }^{*} O D-$ right eye, $O S-$ left eye.

Table 4

Dynamics of psychophysiological functions in VDT workers and the control group

\begin{tabular}{|l|c|c|c|c|c|c|c|}
\hline \multirow{2}{*}{$\begin{array}{c}\text { Psychophysiological } \\
\text { indicator }\end{array}$} & \multicolumn{3}{|c|}{ VDT workers } & \multicolumn{3}{c|}{ Control group } & \multirow{2}{*}{ * } \\
\cline { 2 - 7 } & Before work & Middle & After work & Before work & Middle & After work & P \\
\hline $\begin{array}{l}\text { Visual sensomotor } \\
\text { reaction, ms }\end{array}$ & $243.5 \pm 28.6$ & $257.6 \pm 28.5$ & $275.2 \pm 31.2$ & $241.5 \pm 22.1$ & $245.5 \pm 22.2$ & $250.9 \pm 22.8$ & $<0.01$ \\
\hline $\begin{array}{l}\text { Sound sensomotor } \\
\text { reaction, ms }\end{array}$ & $187.9 \pm 22.3$ & $193.8 \pm 21.8$ & $201.8 \pm 21.5$ & $178.0 \pm 18.9$ & $180.8 \pm 19.2$ & $184.6 \pm 18.9$ & $<0.01$ \\
\hline $\begin{array}{l}\text { Constancy of clear } \\
\text { vision, \% }\end{array}$ & $97.1 \pm 1.5$ & $82.1 \pm 3.2$ & $61.9 \pm 4.2$ & $99.5 \pm 1.3$ & $94.5 \pm 2.6$ & $89.1 \pm 2.5$ & $<0.01$ \\
\hline $\begin{array}{l}\text { Number of changes of } \\
\text { clear-unclear vision } \\
\text { periods, time/min }\end{array}$ & $3.2 \pm 1.0$ & $10.9 \pm 2.3$ & $20.0 \pm 3.0$ & $2.5 \pm 0.8$ & $4.4 \pm 0.9$ & $6.7 \pm 1.0$ & $<0.01$ \\
\hline
\end{tabular}

*comparable reults after work. 
ies show that computer work is associated with significant mental fatigue, as well as the vision analyzers fatigue. This results in the decrease in the working capacity, the most informative indicators of which are shortening of the periods of clear vision, and the elongation of the sound and visual sensomotor reaction.

When analyzing the fatigue of the vision analyzer in the computer operators' group, a comparative analysis of psycho-physiological indicators was performed; it included the comparison of fatigue in people without any symptoms of asthenopia, and those with more than 2 symptoms of this disorder. The findings of this analysis are presented in Table 5 .

Computer operators, who complain of the worsened vision, redness of the eyes, eye pain, and diplopia during their work time, showed more significant changes in the psycho-physiological indicators, objectively reflecting fatigue of the vision analyzer. In the group of people with symptoms of asthenopia, the differences in the indicators of visual sensomotor reaction, the constancy of clear vision, and the changes in the periods of clear and unclear vision were statistically reliably greater than in people without symptoms of visual fatigue.

The evaluation of the dynamics of psycho-physiological indicators during the working week showed that the greatest differences of these indicators were seen during the last working day, i.e. on Friday. This shows that on Fridays the working capacity is the lowest, while fatigue - the highest. According to the results of the psycho-physiological studies, the days characterized by the highest working capacity, were in the middle of the working week. The changes of the psycho-physiological indicators during the working week, expressed in percent, are presented in Table 6 .

\section{Discussion}

Some methodological considerations. The volume of the study was limited, basically in order to make explicit ophthalmologic examinations and fatigue measurements. In addition, the size of the control group (nonVDT users) was smaller due to continuing computerization of this type of workplaces. The mean age of the case subject ( 33.8 years) and the control ( 35.4 years) groups was similar. Age-related changes of the visual organ in this age group are not expressed. This allows to compare the findings of the ophthalmologic study, which would not be possible if the age groups were different. Age-related changes in the vision analyzer weaken the ability of the pupil to change its configuration, which results in the development of farsightedness and changes in the accommodation reserves. The literature data presents contradictory findings on the evaluation of the relationship between asthenopia and age. According to some authors, differences in asthenopia reporting do not appear to be connected with the age ${ }^{2)}$. A typical VDT patient, who most frequently complains of visual fatigue, is a 38 year-old woman who works with a computer for more than 5 hours per day, and has medium-

Relation between asthenopia and psychophysiological indicators

\begin{tabular}{|l|c|c|c|c|c|c|c|}
\hline \multirow{2}{*}{$\begin{array}{l}\text { Psychophysiological } \\
\text { indicator }\end{array}$} & \multicolumn{2}{|c|}{ VDT workers with asthenopia (n=92) } & \multicolumn{2}{c|}{ VDT workers without asthenopia (n = 47) } & \multirow{2}{*}{ P* } \\
\cline { 2 - 7 } & Before work & Middle & After work & Before work & Middle & After work & \\
\hline $\begin{array}{l}\text { Visual sensomotor } \\
\text { reaction, ms }\end{array}$ & $242.6 \pm 21.3$ & $263.4 \pm 26.8$ & $281.2 \pm 29.6$ & $244.9 \pm 19.6$ & $256.2 \pm 18.4$ & $267.5 \pm 20.5$ & $<0.01$ \\
\hline $\begin{array}{l}\text { Sound sensomotor } \\
\text { reaction, ms }\end{array}$ & $186.1 \pm 20.1$ & $194.3 \pm 19.5$ & $205.4 \pm 21.9$ & $188.7 \pm 17.9$ & $192.6 \pm 19.4$ & $201.5 \pm 18.9$ & $>0.05$ \\
\hline $\begin{array}{l}\text { Constancy of clear } \\
\text { vision, \% }\end{array}$ & $96.1 \pm 1.1$ & $79.3 \pm 2.9$ & $57.8 \pm 3.1$ & $98.2 \pm 1.4$ & $85.6 \pm 2.8$ & $64.2 \pm 3.0$ & $<0.01$ \\
\hline $\begin{array}{l}\text { Number of changes of } \\
\text { clear-unclear vision } \\
\text { periods, time/min }\end{array}$ & $3.4 \pm 0.9$ & $12.5 \pm 1.8$ & $22.1 \pm 3.6$ & $2.7 \pm 0.9$ & $8.9 \pm 1.0$ & $17.8 \pm 2.5$ & $<0.01$ \\
\hline
\end{tabular}

*comparable reults after work.

Table 6

Dynamics of psychophysiological indicators during a week*

\begin{tabular}{|c|c|c|c|c|c|}
\hline \multirow{2}{*}{ Indicator } & \multicolumn{5}{|c|}{ Weekday } \\
\hline & I & II & III & IV & V \\
\hline Visual sensomotor reaction, $\mathrm{ms}$ & +26.7 & +31.5 & +34.1 & +31.2 & +37.6 \\
\hline Sound sensomotor reaction, $\mathrm{ms}$ & +13.1 & +13.2 & +13.4 & +14.4 & +14.5 \\
\hline Constancy of clear vision, $\%$ & -33.5 & -34.0 & -34.5 & -36.2 & -37.9 \\
\hline
\end{tabular}

${ }^{*}$ comparable difference before and after the work, $(+)$ mean increase, $(-)-$ decrease. 
degree myopia ${ }^{13)}$. Meanwhile, other authors state that age-related presbiopic changes in the vision analyzer caused the increase of the visual fatigue and more numerous symptoms of asthenopia ${ }^{14)}$. In order to avoid the ambivalently evaluated age factor that could distort the findings, the case and the control groups were selected so that their mean age was similar.

The prevalence of eye disturbances, as determined by the questionnaire in our study (around $88 \%$ ), was greater than that described in other reports ${ }^{3,13-15}$. Comparing the results of different surveys can be difficult due to different work environments and interpretations of the results5). The increased prevalence of asthenopia can be explained by workplace characteristics of our sample in our country with poor ergonomic construction of the working environment. The beginning of computerization in the workplaces, where these studies were performed was very simple: a simple office where «paper» work was done using computers without respect of ergonomic requirements. However, similar working conditions in cases of both the case and the control groups allowed to evaluate the influence of a computer, as an additional element of the workplace, on health and working capacity.

Certainly, there exists a difficulty at the medical level of defining and measuring asthenopia, this being identified as the more or less striking presence of several different disturbances such as unclear, blurred vision, painful and flickering eyes. Unfortunately, it is common, that the term «occupational asthenopia» sometimes is understandable as «eye irritation», «visual fatigue», or «disability glare» ${ }^{13)}$. We used a «medical» definition of asthenopia, defining this condition as a complex of subjective complaints characterized by worsened vision, diplopia, flicker in the eyes, and redness, pain, and soreness of the eye ${ }^{1}{ }^{1}$. In order to define the visual fatigue more precisely, when evaluating psychophysiological functions, and to perform a more precise determination of the relationship between asthenopia and visual fatigue, we selected people with no less than 2 symptoms of asthenopia. The diagnosis of asthenopia in these people was unquestionable.

Objective studies of the visual function show that computer work changes ophthalmologic indicators, i.e. accommodation, vision acuity, and the proximal convergence point. The temporary myopization is one of objective ways of the evaluation of the visual fatigue $2,8,16)$. Narrowing of the refraction power stipulates a more rapid visual fatigue development. People without symptoms of asthenopia are significantly less frequently found to have refraction changes ${ }^{37}$ ).
The values of relative accommodation, and their changes also have a prognostic value. Narrowed accommodation abilities may influence permanent myopization or more pronounced presbiopic changes. Ophthalmic examination of workers aims at the diagnosis and prognosis of suspected or apparent ophthalmic pathologies. These examinations are useful for the establishment of job fitness or future visual capacities of the worker ${ }^{14}$ ). In occupations with VDT work, vision screening should be undertaken to provide a pre-injury record of vision, in order to evaluate the degree and the character of work-related visual impairment ${ }^{18}$. Preventive periodical screenings of vision are useful for decreasing visual fatigue in people when their conditions are provided for inadequately corrected refraction disorders or pathological changes in the visual analyzer.

Undoubtedly, computer work stimulates the development of the dry eye syndrome. This is confirmed by a number of experimental and field studies ${ }^{12,19)}$. The dry eye syndrome is associated with a number of subjective complaints that is the major manifestation of asthenopia. Asthenopia is influenced not only by changes in refraction, but also by changes in lachrymal dynamics. However, it is difficult to evaluate quantitatively to what extent asthenopia is conditioned on the changes in refraction and in the stability of the tear film. According to Nakaishi $\mathrm{H}$ and Yamada Y.19), the odds ratio for the development of asthenopia in the presence of the dry eye syndrome is 4.61 , and in the presence of refractive errors -2.31 . According to the findings of this study, changes in the stability of the lachrymal film greatly influenced the development of asthenopia. However, the dry eye syndrome does not have any influence on changes in refraction during work, the subjective manifestation of those changes was an unclear vision. According to the findings of our study, unclear vision complaint was the main symptom of asthenopia.

The quantitative criteria for the evaluation of the visual fatigue are constantly being searched for. They are useful for a more precise evaluation of the depth of the visual damage at work, the determination of the effect of individual factors of the working environment, and for the design of an optimal working day regimen $^{7-9,14,16,20)}$. A number of examinations of sight are used for the evaluation of visual fatigue, including critical flicker fusion, near point accommodation, convergence, visual acuity, and tests for the ability to maintain concentration $\left.^{9-11}, 16,20,21,27\right)$. VDT work is associated with the impairment of the visual central nervous system function, and not only the vision analyzer. Studies of the central nervous system are performed, involving 
the registration of changes in encephalograms, and the determination of the visual evoked potential latency time. These studies are especially useful for the evaluation of the fatigue of the visual analyzer and the central nervous system ${ }^{21,22)}$. Visual evoked potential latencies appear to be a sensitive indicator of the visual fatigue, at least transiently, and critical flicker fusion (CFF) appears to be a good parameter for estimations of the chronic visual fatigue ${ }^{21}$. Quantitative evaluation of visual fatigue allow to evaluate each worker's fatigue and its dynamics in the course of the day and the week. The findings of such studies increase the effectiveness of individual fatigue prevention programs, and allows to design optimal work schedules. According to the findings of our studies, fatigue of the visual analyzer may be evaluated using the tests for the evaluation of the constancy of clear vision, the changes of the periods of clear-blurred vision, and the visual sensomotor reactions. These tests are simple and may be performed at the workplace.

Some limitations of our work must be pointed out. A possible solution to this problem would be to introduce in future research the evaluation of various stressors of the work environment, and their influence on visual and mental fatigue of workers. This would allow for a more detailed evaluation of the main fatigueforming factors and their combinations. After deter-

\section{References}

1. Mocci F., Serra A. Psychological factors and visual fatigue in working with video display terminals. Occup Environ Med 2001; 58: 267-271.

2. Bergquist $U$. Video display terminals and health. A technical and medical appraisal of the state of the art. Scand J Work Environ Health. 1984; 10, suppl 2: 1-87.

3. Bergqvist U., Knave B. Eye discomfort and work with visual display terminals. Scand $J$ Work Environ Health. 1994: 20 (1): 27-33.

4. Bergquist U., Knave B., Voss M., Wibom R. A longitudinal study of VDT work and health / / Int. J. Human Computer Interaction.- 1992: 4: 197 -219.

5. Scalet E. VDT health and safety, issues and solutions. By Ergosyst Associates, 1987.

6. Nakaishi H., Yamada Y. Abnormal tear dynamics and symptoms of eyestrain in operators of visual display terminals. Occup Environ Med. 1999; 56 (1): 6-9.

7. Gobba FM, Broglia A, Sarti R, Luberto F, Cavalleri A. Visual fatigue in video display terminal operators: objective measure and relation to environmental conditions. Int Arch Occup Environ Health. 1988; 60 (2): 81-7.

8. Hanne W. Brewitt $H$. Changes in visual function caused by work at a data display terminal. Ophthalmologe. 1994: 91 (1): 107-12 (in German with English abstract). mining the factors that mostly influence psycho-physiological changes at work, it would be possible to apply maximally effective interventional and preventive measures. This approach, which has been used in the research, seems to be the most promising.

\section{Conclusions}

The occurrence of visual fatigue due to VDT work was confirmed by ophthalmologic and psycho-physiological measurements, as well as by the reported subjective symptoms of asthenopia. Our results suggest that changes in the ocular and psychophysiological functions before and at the end of the workday, as determined in our study, provide for a good objective index of VDT-induced «ocular» and central nervous system fatigue. More easily accessible and simple examinations may be used for the evaluation of fatigue at the workplace within the framework of preventive programs of interventional studies. However, prior to the employment of a person to a computer work, ophthalmologic examination should be performed in order to detect possible refractive errors of ophthalmologic pathologies.

\section{Acknowledgments: \\ The authors wish to acknowledge the financial support provided by the Lithuanian State Science and Studies Foundation for conducting the study.}

9. Lantsburg M.E, Moikin I.V, Rozenblium I Z.. The dependence of the degree of visual fatigue on the shift duration in work with video terminals and an assessment of the efficacy of preventive measures Gig Tr Prof Zabol. 1992; 4: 12-5 (In Russian with English abstract).

10. Saito S., Sotoyama M., Saito S., Taptagaporn S. Physiological indices of visual fatigue due to VDT operation: pupillary reflexes and accommodative responses. Ind Health. 1994; 32 (2): 57-66.

11. Murata K., Araki S., Yokoyama K., Yamashita K., Okumatsu T., Sakou S. Accumulation of VDT workrelated visual fatigue assessed by visual evoked potential, near point distance and critical flicker fusion. Ind Health. 1996; 34 (2): 61-9.

12. Nakaishi H., Yamada Y. Abnormal tear dynamics and symptoms of eyestrain in operators of visual display terminals. OccupEnviron Med 1999; 56: 6-9.

13. Salibello C., Nilsen E. Is there a typical VDT patient? A demographic analysis. J Am Optom Assoc. 1995; 66 (8): 479-83.

14. Piccoli B. A critical appraisal of current knowledge and future directions of ergophtalmology: consensus document of the ICOOH Committee on 'Work and vision'. Ergonomics 2003; 46 (4): 384-406. 
15. Cole BL. Do video display units cause visual problems? - a bedside story about the processes of public health decision-making. Clin Exp Optom. 2003; 86 (4): 205-20.

16. Thomson David W. Eye problems and visual display terminals - the facts and the fallacies. Ophthal Physiol Opt 1998; 18 (2): 111-119.

17. Koicheva V, Tsaneva L, Stanchev V. Changes in the functional state of the visual analyzer in operators working with video display terminals. Gig Tr Prof Zabol. 1991; 8: 5-6 (In Russian with English abstract).

18. Luberto F, Gobba F, Broglia A. Temporary myopia and subjective symptoms in video display terminal operators. Med Lav. 1989; 80 (2): 155-63 (In Italian with English abstract).

19. Tsubota K, Nakamori K. Dry eyes and video display terminals. N Engl J Med. 1993; 328 (8): 584-589.

20. Borodulin-Nadzieja L, Salomon E, Janocha A. The influence of computer work on reaction time and accuracy in VDT operators. Med Pr. 1997; 48 (2): 139-44 (In Polish with English abstract).

\section{Рута Устинавичене, Виммантас Янушісявичюс ИНАИКАТОРЫ СНИКЕНИЯ ЗРИТЕАЬНОЙ ФУНКШИИ ПРИ РАБОТЕ С ВИАЕОТЕРМИНАМАМИ}

Каунасский мемишинский университет, Каунас, литва

Оценка связи между функциональными показателями усталости органа зрения и симптомами астенопии производилась на основе определения связи между субъективными и объективными показателями усталости органа зрения. Когорта обследованных состояла из 404 работников учреждений, как с наличием, так и без наличия необходимости работы на видеотерминалах. Для оценки усталости органа зрения была использована разработанная анкета-опросник, с субъективными показателями и с результатами объективного исследования основных офтальмологических показателей. Психофизиологические исследования включали оценку изменений сенсомоторной реакции в течение рабочего дня и рабочей недели; кроме того изучалось соотношение ясного и не ясного видения. Оценка психофизиологических показателей проводилась в течение одной рабочей недели (пять дней с понедельника). Ежедневные замеры включали проведение обследования три раза в день. Результаты анкетного опроса показали, что 88,4 \% служаших жаловались на различные расстройства работы органа зрения. Результаты психофизиологических исследований показали, что в течение второй половины рабочего дня, при развитии общей усталости и астенопии, отмечены офтальмологические изменения: замедляется сенсомоторная реакция, продолжительность периодов неясного видения становится больше, смена периодов ясного и неясного видения происходит быстрее. Изменения офтальмологических функций и психофизиологических показателей в начале и в конце рабочего дня показывают достоверные изменения центральной и периферической «глазной» усталости при работе на VDT. Полученные результаты могут быть использованы для профилактических «интервенционных» исследований.

Ключевые слова: эргофтальмология, визуальная усталость, профессиональная астенопия, работа за видеотерминалом, офтальмологический дискомфорт, психофизиология

Поступила: 04.07.2007 2.

Correspondence to: Ustinaviciene Ruta, Department of Environmental and Occupational Medicine, Kaunas University of Medicine, A.Mickeviciaus str., 9, LT - 44307, Kaunas, Lithuania, e-mail: ruta.ustinaviciene@med.kmu.lt. 